\title{
Detection and Genotyping of Human Papillomavirus in Cervical Tissue Samples in Ahvaz, Southwest Iran
}

\author{
Mojtaba Hamidi-Fard ${ }^{1}$, Mojtaba Fattahi-Abdizadeh ${ }^{1}$, Manoochehr Makvandi ${ }^{1}$, Nastaran \\ Ranjbari ${ }^{2}$, Esrafil Mansoori ${ }^{3}$, Alireza Samarbaf-Zadeh ${ }^{1,{ }^{*}}$ \\ 1 Department of Virology, Ahvaz Jundishapur University of Medical Sciences, Ahvaz, IR Iran \\ 2 Department of Pathology, Imam Khomeini Hospital, Ahvaz, IR Iran \\ 3 Department of Anatomical sciences, Ahvaz Jundishapur University of Medical Sciences, Ahvaz, IR Iran \\ ${ }^{*}$ Corresponding author: Alireza Samarbaf-Zadeh, Department of Virology, Ahvaz Jundishapur University of Medical Sciences, Ahvaz, IR Iran. Tel:+98-6113361543 Fax:+98-6113361544, \\ E-mail:alirezasamarbaf_78@hotmail.com.
}

Received: May 19, 2012 ; Revised: Jul 31, 2012; Accepted: Oct 22, 2012

\begin{abstract}
Background:500,000 new cases with progressive cancer of cervix are reported worldwide annually. This malignant cancer is the second common cancer among females. Human papillomavirus (HPV) is considered as the major cause of cervical cancer and dysplasia. PCR Application to detect the HPV DNA in clinical specimens besides microscopic examination of cervical biopsy (Papanicolaou smear) (Pap smear) are valuable prognostic indicators in cervical cancer management.

Objectives: Due to the absence of epidemiological data on prevalence and distribution of HPV genotypes in Khuzestan province, the authors decided to conduct a research to determine the HPV genotypes in cases with a degree of cervical dysplasia.

Materials and Methods: In this study, 60 samples of paraffin-embedded biopsy samples archived in the library of pathology laboratory of Ahvaz Imam Khomeini hospital were selected for further experiments. After DNA extraction of each specimen, the infection of the tissue with HPV was confirmed by PCR. PCR products were sequenced to detect HPV genotypes.

Results: Out of 60 cervical biopsy samples, 8 (\%13.3) cases were HPV DNA positive. Four (\%50) were genotype 16 positive, 2 (\%25) were genotype 6 positive, $1(\% 12.5)$ sample was detected as the genotype 18 and 1 of the positive cases was genotype 11 of HPV.

Conclusions: Our study shows that prevalence of HPV infection in cervical biopsy samples collected from suspected patients in Khouzestan province is slightly higher than other provinces of Iran. Since HPV cervical infection, is an indicator for the host cervical cancer progression, parallel with Pap smear test, PCR detection of HPV DNA in biopsy of suspected cases is recommended.
\end{abstract}

Keywords: Human Papillomavirus; Genotypes; PCR; Iran

\section{Background}

Cervical cancer is the second common women malignancy all over the world. Although routine screening of suspected cases by Pap smear has reduced the cervical cancer mortality rate, reports from over the world indicate that still 500,000 new cases of progressive cervical cancer are emerging annually (1). Human papillomavirus (HPV) is a double-stranded DNA virus and a member of Papillomaviridae family. About 118 species of this family have been known till now. Members of 5 genus of this family including alpha papillomavirus harbor some of human organelles. Forty types of alphapa pillomavirus infect human female genital tracts. Some members of this genus including genotypes $16,18,31,33,35,39,45,51$, 52, 56, 5859 and 66 are responsible for human cervical, mucosal anogenital, head and neck cancers $(1,2)$.

Persistent HPV infection might lead to cervical intraepi- thelial neoplasia (CIN 2, 3) and Adenocarcinoma In-Situ (AIS), and in case of untreated, would increase the cancer risk (3). Regular gynecological screening and swift clinical diagnosis of precancerous lesions are significant preventive measurements of cervical cancer (1). Permanent expression of HPV E6 and E7 in human cell lines, stimulates the transformation of human cells. Expression of these viral proteins is required to ensure the proliferative stage of infected cells. These proteins can deregulate the host cell growth cycle by binding and inactivating tumor suppressor proteins, cell cyclins, and cyclin-dependent kinases (4).

Currently the most common screening test used for cervical cancer is Pap smear. In this test the cytomorphology of the cervical cells are evaluated and the degree of abnormal cells are determined and graded. Pap smear is a highly specific and screening test through this test the incidence of cervical cancer following detection has

Implication for health policy/practice/research/medical education: We performed this study to understand the role of infection in ahvaz female cancer patients.

Copyright @ 2013, Ahvaz Jundishapur University of Medical Sciences; Licensee Kowsar Ltd. This is an Open Access article distributed under the terms of the Creative Commons Attribution License (http://creativecommons.org/licenses/by/3.0), which permits unrestricted use, distribution, and reproduction in any medium, provided the original work is properly cited. 
been lowered. Sampling process, spreading of the cells on microscopic slides, fixation of the slides, staining of the smears and pathologist expertise are interfered in the specificity of the Pap smear $(1,5)$. On the other hand, the Pap smear sensitivity is low (25-50\%) so that false negative results are common $(6,7)$. Reports show that some of the false negative results related to progressing cervical neoplasia (CIN) (8). PCR test to detect HPV DNA is highly sensitive (6) and has been recommended for detection of CIN in parallel to cytological tests, and it has been shown that PCR analysis of Pap smear considerably improved the chances of CIN 2,3 detection $(8,9)$.

\section{Objectives}

According to the important HPV role on cervical cancer incidence, and recommendation of HPV detection by in combination of Pap smear for the mentioned purposes, the aim of this study was to detect and genotype HPV strains obtained from cervical tissues. Consequently, the results of present study might help physicians to prognosis and manage cervicalneoplasia and abnormalities. Also it can fill the gaps on epidemiological data about HPV genotypes distribution in Iran.

\section{Materials and Methods}

\subsection{Sample Collection}

Sixty paraffin-embedded collected cervical biopsy samples from the patients with warts, protruded tissue mass, skin scars, or pain. These criteria were used for sampling from the patients referred to the pathology department of Ahvaz Imam Khomeini hospital from January 2009 to December 2010. The other considered citeria were the age of the patients ( $>15$ years old) and abnormal histological report. The blocks of biopsy samples were transferred to virology laboratory of university.

\subsection{Preparation of Biopsies to Extract the DNA}

3 sections from each block were prepared. The diameter of each section was $10 \mu \mathrm{m}$. The biopsy sections were placed into $1.5 \mathrm{~mL}$ DNase free microtubes. For deparaffinization, $1 \mathrm{~mL}$ xylene was added in each tube and the tubes were incubated at $45^{\circ} \mathrm{C}$. After 15 minutes the xylene was removed. This step was performed two times. To completely remove the remaining amount of xylene, the tissue was washed with ethanol $90 \%$ and then ethanol $70 \%$. The tubes were kept at room temperature with opened cap to completely evaporate ethanol.

\subsection{DNA Extraction}

DNA was extracted from deparaffinized biopsy sections by DNP kit(Cinnagen, Iran). Each sample was treated with a buffer supplied by kit and Proteinase Kand incubated at $55^{\circ} \mathrm{C}$ for 3 hours, the lysis buffer was added and vortexed for 20 seconds. At this step the tissue was completely di- gested and a clear solution was obtained. Then precipitation solution of the kit was added to the tube and the tube was centrifuged for 10 minutes at $12000 \mathrm{rpm}$. The pellet s washed twice with ethanol. Ethanol was removed and the tubes were stand at room temperature uncapped for about 5 minutes to evaporate ethanol completely. DNA pellet was dissolved in $50 \mu \mathrm{L}$ DNase-free high-quality grade water (Millipore, USA). DNA was saved as template of PCR test at $-20^{\circ} \mathrm{C}$.

\subsection{PCR}

At first, the absence of PCR inhibitors was evaluated using $\beta$-Globin primers (10). Then HPV DNA PCR reaction was prepared in $50 \mu \mathrm{L}$ volume (11). The PCR reaction contained $5 \mu \mathrm{L}$ DNA template, $1 \mu \mathrm{L}$ dNTPs $(10 \mathrm{mM}), 0.3 \mu \mathrm{L}$ Taq DNA polymerase $(5 \mathrm{U} / \mu \mathrm{L}), 5 \mu \mathrm{L} 10 \mathrm{X}$ PCR buffer, $1 \mu$ of each GP5+ and GP6+ primers (30 pmol), and 36.7 $\mu \mathrm{L}$ DNase free UHQ. PCR components were purchased from Roche (Germany). Themocycler (TC-512, Techne, UK) was programmed as follow: Initial denaturation, at $95^{\circ} \mathrm{C}$ for 5 minutes, then 35 cycles of: denaturation $\mathrm{Tm}, 95^{\circ} \mathrm{C}$ for 40 seconds, annealing $\mathrm{Tm}, 40^{\circ} \mathrm{C}$ for 40 seconds, and extension $\mathrm{Tm}$ was $72^{\circ} \mathrm{C}$ for 45 seconds. The final extension cycle was $72^{\circ} \mathrm{C}$ for 3 minutes. Six $\mu \mathrm{L}$ of PCR products were loaded on the $1.5 \%$ agarose gel and electrophoresed for about 1 hour at 100 volts. Following ethydium bromide staining the gel was visualized on UV Transiluminater

Figure 1 Electrophoresis Gel of PCR Products

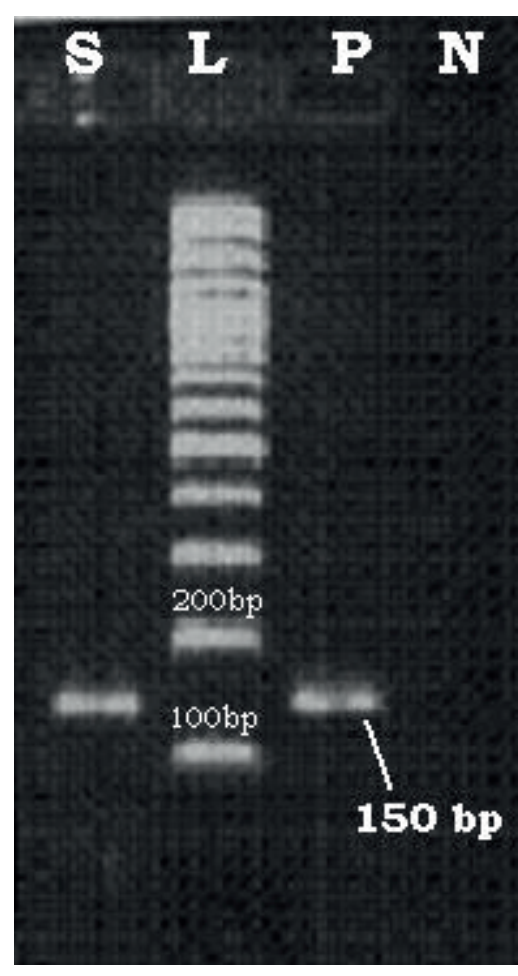

A 150 bp band is visible in the HPV DNA positive sample.N, negative control; P, positive control; L, 10obp DNA molecular weight marker; $S$, sample 
(Vilber Lourmat, France). A DNA band with 150bp was considered as a positive sample and subjected to genotyping. In all PCR tests a positive and negative control was included. One sample (obtained from Dr. Keyvani, Keyvan virology lab, Tehran, Iran) that previously determined positive for HPV DNA was used as positive control and DNA extraction product of a liver biopsy sample was used as negative control.

\subsection{Genotyping}

The genotype of HPV PCR positive samples were determined based on evaluation of PCR product sequences. PCR product of HPV DNA positive samples were separated by agarose gel electrophoresis and purified using the High Pure PCR Product Purification Kit (Roche, Germany). Purified products were sequenced by Bioneer Company (South Korea). Nucleotide sequences were corrected by visual inspection. Sequences were compared to HPV sequences available at Gene bank database at http:// ncbi.nlm.nih.gov/ using BLAST. Moreover, to evaluate the genetic distances and phylogenetic tree, the sequences were aligned with Clustal W program using Molecular Evolutionary Genetics Analysis (MEGA) software version 5.0 (12) followed by construction of phylogenetic tree based on the Neighbor-Joining (NJ) algorithm (13). Finally, HPV genotypes were identified using BLAST and phylogenetic tree data.

\section{Results}

\subsection{PCR}

Sixty biopsy samples from the archive of pathology department, Ahvaz Imam Khomeini hospital were analyzed. The mean age of patients was 45 years (age range of 25-81 years old). Out of 60 samples, 8 specimens (13.3\%) were positive for HPV DNA. Figure 1 shows the PCR results of HPV DNA positive samples.

\subsection{Genotyping}

After multiple sequence alignment, the phylogenetic tree was constructed (Figure 2) using molecular evolutionary genetics analysis (MEGA) software version 5.0 (13). Based on BLAST and phylogenetic tree information, the HPV genotypes were determined. Four HPV DNA positive samples (50\%) were identified as genotype 16, 2 (25\%) were determined as genotype 6,1 positive sample $(12.5 \%)$ was detected as genotype 18 and 1positive sample (12.5\%) was identified as genotype 11 .

Figure 2. Phylogenetic Tree of HPV DNA Positive Samples

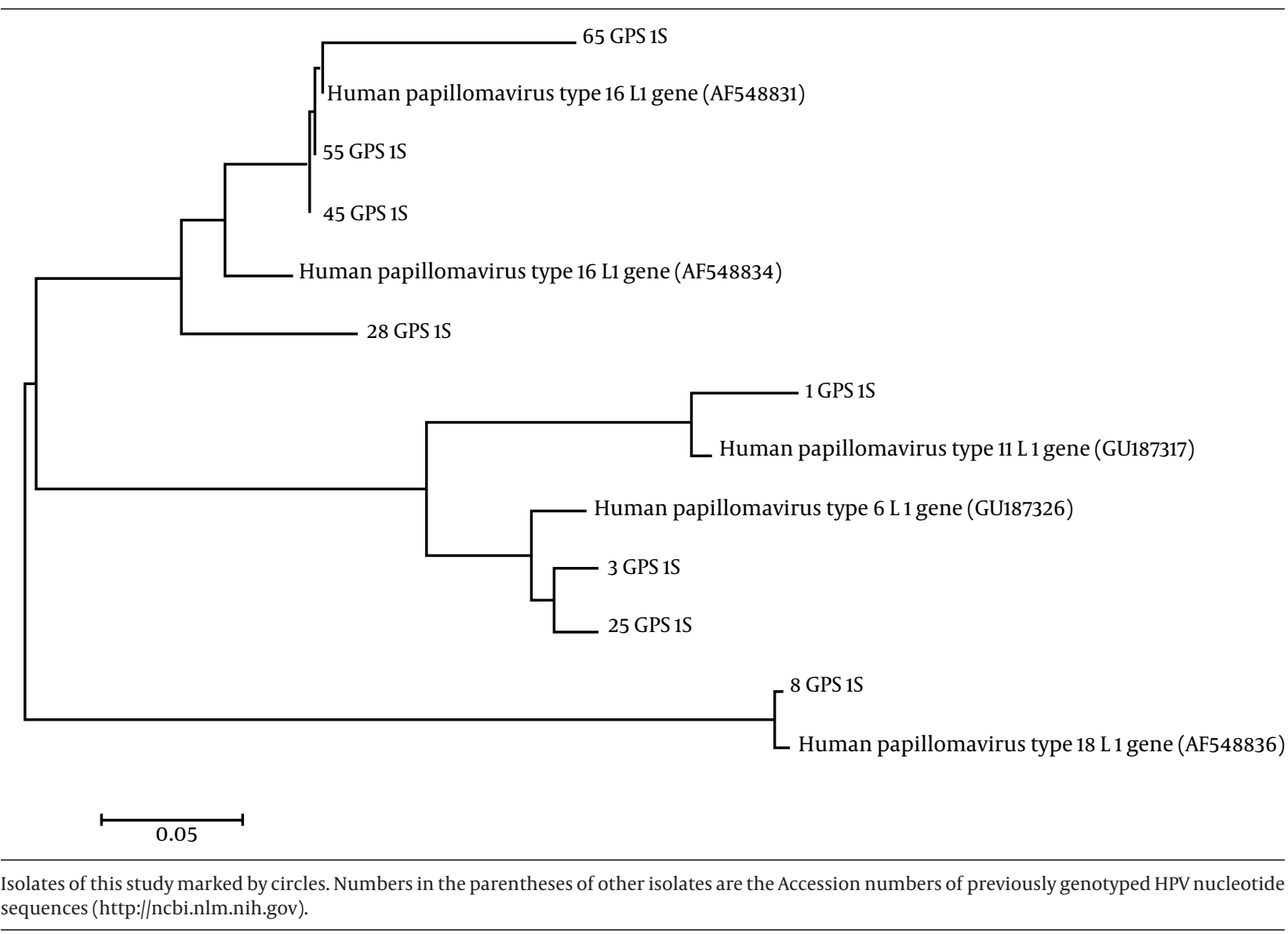




\section{Discussion}

Cervical carcinoma is the second most prevalent female cancer worldwide (1). The survive of thousands of patients would be possible by rapid detection of this cancer. Positive HPV PCR is considered as a prognostic indicator of HPV cervical cancer and combination of PCR and cytological test have already applied for rapid diagnosis of CIN 2, 3 in the early-stage of the disease $(6-10,14)$. Since HPV is not routinely cultivable, the best techniques for detection of HPV are through molecular techniques such as PCR and genotyping. For above mentioned reasons we have decided to detect and genotype the HPV obtained from the cervical biopsy specimens. Besides, there is no information about predominant genotype of HPV among cervical biopsy samples in Khouzestan.

In this study, following PCR of the cervical biopsy samples and genotyping of the products, the result showed that the predominant genotype of HPV in Iran (Khouzestan) is HPV-16. This result is accordance to other studies performed in other parts of the world (7, 15-17). When HPV infection was determined by specific probes of 16 and 18 genotypes (high risk HPVs), both genotypes were reported as dominant $\operatorname{HPVs}(18,19)$. The prevalence of HPV in cases with abnormal Pap smears or squamous cell carcinoma (SCC) was 24-67\% (15-18). These records were reported 5.5-35\% in cases with normal Pap smear results $(7,15,17,18,20)$.

Similar screening studies performed to assess the HPV prevalence in normal Pap smears or normal biopsy samples in Iran,, demonstrated that $5.5-9 \%$ of the specimens were HPV positive $(7,18)$. The HPV prevalence in the present study was $13.3 \%$.This amount was lower compared with the reported statistics of HPV in other parts of the world $(15,17,20)$. Since detection of HPV is a more sensitive technique than cytomorphology and false negative results of the previous technique is overcome, we suggest detection of HPV along with cytomorphological test to this purpose. It could be a useful prognostic indicator in early-stage of and cervical cancer.

\section{Acknowledgements}

This study was supported by a grant from research center of infectious and tropical diseases, Ahvaz Jundishapur University of medical sciences.

\section{Authors' Contribution}

Alireza Samarbaf-Zadeh: Project suggestion and supervisor of the experiment, reviewer of the paper. Mojtaba Hamidi-Fard and Motaba Fattahi. Test Experiment. Manoocher Makvandi: Supervising of the experiment. Nastaran Rajabi: Pathology sample provider. Esrafil Mansoori: Pathology sample preparation

\section{Financial Disclosure}

No conflict of interest.

\section{Funding/Support}

Research Center of infectious and tropical diseases, Ahvaz Jundishapur University of Medical Sciences.No. Project:88105

\section{References}

1. Cutts FT, Franceschi S, Goldie S, Castellsague X, de Sanjose S, Garnett $G$, et al. Human papillomavirus and HPV vaccines: a review. Bull World Health Organ. 2007;85(9):719-26.

2. de Villiers EM, Fauquet C, Broker TR, Bernard HU, zur Hausen $\mathrm{H}$. Classification of papillomaviruses. Virology. 2004;324(1):17-27.

3. Ostor AG. Natural history of cervical intraepithelial neoplasia: a critical review. Int J Gynecol Pathol.1993;12(2):186-92.

4. zur Hausen H. Papillomaviruses causing cancer: evasion from host-cell control in early events in carcinogenesis. J Natl Cancer Inst. 2000;92(9):690-8.

5. Das BC, Gopalkrishna V, Hedau S, Katiyar S. Cancer of the uterine cervix and Human Papillomavirus infection. Curr Sci. 2000;78:5263.

6. Kulasingam SL, Hughes JP, Kiviat NB. Evaluation of human papillomavirus testing in primary screening for cervical abnormalities: Comparison of sensitivity, specificity, and frequency of referral. JAMA. 2002;288(14):1749-57.

7. Zandi K, Eghbali SS, Hamkar R, Ahmadi S, Ramedani E, Deilami I, et al. Prevalence of various human papillomavirus (HPV) genotypes among women who subjected to routine Pap smear test in Bushehr city (south west of Iran) 2008-2009. Virol J. 2010;7:65.

8. Nanda K, McCrory DC, Myers ER, Bastian LA, Hasselblad V, Hickey JD, et al. Accuracy of the Papanicolaou test in screening for and follow-up of cervical cytologic abnormalities: a systematic review. Ann Intern Med. 2000;132(10):810-9.

9. Cuzick J, Beverley E, Ho L, Terry G, Sapper H, Mielzynska I, et al HPV testing in primary screening of older women. Br J Cancer. 1999;81(3):554-8.

10. Sankaranarayanan R, Budukh AM, Rajkumar R. Effective screening programmes for cervical cancer in low- and middle-income developing countries. Bull World Health Organ. 2001;79(10):95462.

11. de Roda Husman AM, Walboomers JM, van den Brule AJ, Meijer CJ, Snijders PJ. The use of general primers GP5 and GP6 elongated at their 3 ' ends with adjacent highly conserved sequences improves human papillomavirus detection by PCR. J Gen Virol. 1995;76 ( Pt 4):1057-62.

12. Tamura K, Peterson D, Peterson N, Stecher G, Nei M, Kumar S MEGA5: molecular evolutionary genetics analysis using maximum likelihood, evolutionary distance, and maximum parsimony methods. Mol Biol Evol. 2011;28(10):2731-9.

13. Tamura K, Nei M. Estimation of the number of nucleotide substitutions in the control region of mitochondrial DNA in humans and chimpanzees. Mol Biol Evol.1993;10(3):512-26.

14. Mandelblatt JS, Lawrence WF, Womack S, et al. . BEnefits and costs of using hpv testing to screen for cervical cancer. JAMA. 2002;287(18):2372-81.

15. Grahovac M, Racic I, Hadzisejdic I, Doric A, Grahovac B. Prevalence of human papillomavirus among Croatian women attending regular gynecological visit. Coll Antropol. 2007;31 Suppl 2:73-7.

16. Niakan M, Yarandi F, Entezar M. Human papillomavirus (HPV) detection in biopsies from cervical cancer patients; A population-based study from Iran. Iran J Clin Infect Dis. 2009;4(1):35-7.

17. Lee Kyung-Ok, Jeong Su-Jin, Park Min-Young, Seong Hye-Soon, Shin Eun-Sim, Choi Kyeong-Hwan, et al. Prevalence of Human Papillomavirus Genotypes in Routine Pap Smear of 2,562 Korean Women Determined by PCR-DNA Sequencing. J Bacteriol Virol. 2009;39(4):337-44.

18. Hamkar R, Azad TM, Mahmoodi M, Seyedirashti S, Severini A, Nategh R. Prevalence of human papillomavirus in Mazandaran Province, Islamic Republic of Iran. East Mediterr Health J. 2002;8(6):805-11.

19. Chan PK, Chang AR, Tam WH, Cheung JL, Cheng AF. Prevalence 


\section{Hamidi-Fard M et al.}

and genotype distribution of cervical human papillomavirus infection: Comparison between pregnant women and non-pregnant controls. J Med Virol. 2002;67(4):583-8.
20. Smith JS, Melendy A, Rana RK, Pimenta JM. Age-specific prevalence of infection with human papillomavirus in females: a global review. J Adolesc Health. 2008;43(4 Suppl):S5-25. 